\title{
KEY AUDIT MATTERS OF INDEPENDENT AUDIT REPORTS AND A RESEARCH ON IMPLEMENTATIONS
}

\author{
DOI: 10.17261/Pressacademia.2019.1084 \\ PAP- V.9-2019(31)-p.155-159
}

Oktay Tas ${ }^{1}$, Huseyin Mert ${ }^{2}$, Alev Varcan Baskaya ${ }^{3}$

${ }^{1}$ Istanbul Technical University, Management Engineering, İstanbul, Turkey. tasokta@itu.edu.tr, ORCID ID: 0000-0002-7570-549X.

${ }^{2}$ Istanbul Okan University, Social Sciences Institute, i̇stanbul, Turkey. huseyin.mert@okan.edu.tr, ORCID ID: 0000-0001-5391-7865.

${ }_{3}^{3}$ stanbul Okan University, Social Sciences Institute, istanbul, Turkey. avarcan@stu.okan.edu.tr, ORCID ID: 0000-0002-5467-5324.

To cite this document

Tas O., Mert H., Varcan Baskaya A., (2019). Key audit matters of independent audit reports and a research on implementations.

PressAcademia Procedia (PAP), V.9, p.155-159

Permemant link to this document: http://doi.org/10.17261/Pressacademia.2019.1084

Copyright: Published by PressAcademia and limited licenced re-use rights only.

\section{ABSTRACT}

Purpose- Due to the need of increasing transparency about the audit reports, the new standart of audit, 'Key Audit Matters' has been developed. In this study, the execution of new standart was examined in 2018 is the second year of Key Audit Matters implementation in Turkey.

Methodology- In this study, audit reports of publicly traded companies, have been analyzed in terms of Key Audit Matters for the years 2017 and 2018.

Findings- According to result of this study, it was observed that standardized, generic or technical matters had been defined as Key Audit Matters, with common details.

Conclusion- It was concluded that, the implementation of Key Audit Standard in Turkey would be effective within the years. According to defined standart IAS701, Key Audit Matters should be specified to the entity, in order to provide relevant information to audit report users.

Keywords: ISA 701, key audit matters, independent audit report, independent audit standarts

JEL Codes: M40, M41, M42, M49

\section{BAĞIMSIZ DENETIM RAPORLARINDA KILIT DENETIM KONULARI VE UYGULAMAYA DÖNÜK BİR ARAŞTIRMA}

\section{ÖZET}

Amaç- Denetim raporu kullanıcılarının artan şeffaflık ihtiyacı ve talebi doğrultusunda uygulamaya alınan BDS 701 'Kilit Denetim Konuları' standardının ülkemizde uygulandığı ikinci yılda, denetçi raporlarında standardın uygulaması, içerik ve detaylar açısından ele alınmıştır. Standardın amacı olan şirkete ait önceli konuların belirlenmesi ve yapılan açıklamaların kapsamları analiz edilirken, 2017 ve 2018 yılları raporları karşılaştırılarak, standardın uygulanmasındaki gelişim incelenmiştir.

Yöntem- Bu çalışma kapsamında Halka Açık şirketlerin 2017 ve 2018 denetim raporları, yer verilen Kilit Denetim Konuları analiz edilerek, kapsam ve açıklamalar açısından karşılaştırılarak yorumlanmıştır.

Bulgular- BDS 701 kapsamında 'Kilit Denetim Konuları' tespitinde ve raporlarda ele alınma şeklinde, sektörel bazda ağırıklı olmak üzere, benzer konuların öne çıktığı, yer verilen konuların ele alınışı ve açıklamalarında daha çok genel ifadeleri kullanıldığı tespit edilmiştir.

Sonuç- Standardın uygulamaya yeni alınmış olmasını göz önüne alarak, ilerleyen yıllarda Kilit Denetim Konuları seçimi ve raporlarda ele alınış şekillerinin standardın hedefine ulaşacağı beklenmektedir. Böylece standardın amacına bağlı olarak şirket faaliyetleri açısından öncelikli konuların belirlenmesi ve yapılacak açıklamalarda genel ifadeler yerine ilgili şirket için özel açıklamalar yapılmasıyla, bilgi kullanıcılarının ihtiyacını karşılama açısından etkinliğinden söz edilebilecektir.

Anahtar Kelimeler: BDS 701, kilit denetim konulari, bağimsiz denetim raporu, bağimsiz denetim standartlari JEL Kodları: M40, M41, M42, M49 


\section{GíRiş}

Hızla ilerleyen teknoloji, işletmelerin faaliyetlerine ve performanslarına ilişkin kullanılabilir veri miktarının da hızla artmasına neden olmaktadır. Büyük miktarlara ve detaylı sınıflandırmalara ulaşan işletme verileri aynı zamanda teknoloji sayesinde hızla raporlanarak, bilgi kullanıcılarına ulaşabilmektedir. Tüm dünyada artan rekabet ve karmaşıklaşan ekonomik koşullar, bilgi kullanıcılarının hızlı karar vermelerini gerekli kılarken, raporlanan bilgilerin güvenilir olmasının önemi de artmaktadır. İşletme yönetimlerinin hazırladığı finansal tabloların, makul güvencesini veren bağımsız denetim raporlarının değişen koşullara göre artan güvenilirlik ihtiyacını karşılayacak şekilde geliştirilmesi de kaçınılmaz olmuştur.

Kilit Denetim Konuları (KDK)'nın Bağımsız Denetçi Raporunda Bildirilmesi Standardı, BDS 701, yürütülen denetime ilişkin daha fazla şeffaflık sağlayarak denetçi raporunun iletişim değerinin arttırılması amacıyla, Türkiye'de 09.03.2017 tarihinde Resmi Gazete'de yayımlanarak duyurulmuştur. Yürürlüğe girişi, borsada işlem gören şirketler için 01.01 .2017 tarihi ve sonrasında, 6102 sayılı Türk Ticaret Kanunu uyarınca bağımsız denetime tabi diğer şirketlerde 01.01.2018 tarihi ve sonrasında başlayan hesap dönemlerinde uygulanmak üzere gerçekleşmiştir.

KDK uygulaması ile denetçinin mesleki muhakemesine göre, cari döneme ait finansal tabloların denetiminde en çok önem arz eden konuların belirlenmesi yoluyla finansal tabloların hedef kullanıcılarına ilave bilgiler sunulması hedeflenmektedir.

\section{LITERATÜR INCELEMESi}

Kamu Gözetim Kurumu, KDKnın belirlenmesini, denetçinin üst yönetimden sorumlu olanlara bildirilen konular arasından, denetimin yürütülmesi sırasında azami düzeyde dikkat edilmesi gereken konuların arasından seçilmesi olarak açıklar. Denetçinin bu belirlemeyi yaparken göz önünde bulunduracağı hususlar, önemli yanlışlık riski daha yüksek olarak değerlendirilen veya ciddi riskli olduğu belirlenen alanlar, yüksek tahmin belirsizliğine sahip olduğu belirlenen muhasebe tahminleri dâhil yönetimin önemli yargılarını içeren finansal tablo ve dönem içinde gerçekleşen önemli olay veya işlemlerin denetime olan etkileridir. Denetçi, bu belirlenen konulardan hangilerinin cari döneme ait finansal tabloların denetiminde en çok önem arz ettiğini belirlerler ve bunlar KDKları oluşturur. KDK'lar için herhangi bir sayısal sınırlama veya yönlendirme yoktur. Konuların seçimi, ele alınması ve açıklanmasında denetçiler arasında fark olabileceği yine kurum tarafından belirtilmiştir. Düzenleme denetçi raporunda yer alan her bir KDK'nın içermesi zorunlu olan unsurları, konunun neden KDK olarak belirlendiği, konunun denetimde nasıl ele alındığı ve varsa finansal tablolardaki ilgili açıklamalara atıf yapılması, olarak belirlemiştir (BDS 701, 9-13.bölümler).

Doğan (2018), çalışmasında BDS 701'in uygulamasını 2017 yılı için incelerken, KDK olarak seçilen konuların içeriklerini açıklamıştır. Türkiye'deki ve dünyadaki uygulamalardan örnekler verdiği söz konusu çalışmasında, KDK'larının mutlaka şirkete özel olarak belirlenmesi gerektiğine ve hatta ihtiyaca göre denetim firmalarının, farklı şirketlerin teknik ve risk değerlendirmelerini yapabilecek kadro düzenlemelerine gitmelerinin gerekli olabileceğine dikkat çekmiştir.

BIST 100 şirketlerinin 2017 yılı denetçi raporlarında yer alan KDK'larının incelendiği çalışmasında Kavut ve Güngör (2018), aynı sektördeki şirketlerde belli konuların ağırlık kazanmış olduğunu tespit ederek, farklı denetçilerin aynı sektörler için benzer konuları önemli bulduklarını belirtmişlerdir. Kavut ve Güngör (2018), KDK uygulamasından beklenen yararın elde edilebilmesi için, konuların anlaşılır bir dille yazılması, uzun anlatımlar ve gerekli olmayan açıklamalardan ve özellikle konuya ilişkin ayrı bir görüş verildiği izleniminden kaçınılması gerektiğini vurgulamışlardır.

Dünyada değişen ekonomik düzenin bir gereği olarak, bilgi kullanıcıları için önemli bir işleve sahip denetim raporlarının son yıllarda geçirdiği değişimi ele alan Yanık ve Karataş (2017), bu çalışmalarında denetim raporundaki değişimi farklı ülkeler için değerlendirmişlerdir. Yine bu çalışmada, KDK'ların raporlarda yer alması ile yatırımcıların daha önceden sahip olunamayan bilgilere ulaşma ve şirketler arasında karşılaştırma yapabilme şansına sahip olabileceklerine dikkat çekmişlerdir.

Apollos, Onuoha ve Aguguom (2016), iş hayatı ve küreselleşen ekonomiyle bağlantılı değişen şartların gereği olarak denetçi raporundan beklentiler ve değişen rapor standartlarının bu beklentiyi karşılayıp karşılamadığını araştırmışlardır. Değişen standartlar kadar, bu standartların beklentileri karşılamasının uygulamada denetçinin performansına bağlı olduğunu belirtmişlerdir. Aynı çalışmada, KDK'ları da dâhil olmak üzere, son dönemde yapılan yeniliklerin uygulanmasında denetçilerin kendi aralarında ve denetlenen şirket yönetimleri ile yakın temasta olmalarının denetim raporlarından beklenen faydanın sağlanmasındaki role dikkat çekerler. Onlara göre, söz konusu yakın temas, yeni düzenlemelerin hızla ve etkin şekilde uygulamada yerini almasını sağlayacaktır.

Araştırmalarında Borsa İstanbul'a kayıtlı 400 şirket için 2017 yılı bağımsız denetçi raporlarındaki KDK'larını inceleyen Ciğer, Çopur Vardar ve Kınay (2018), benzer konuları gruplayarak toplam 32 başlıkta KDK'ları ele alarak, şirketleri farklı gruplara ve KDK'larına göre istatistiksel olarak raporlamışlardır. Çalışmada, farklı ülkelerde yapılan benzer çalışmaların verilerine de yer verilerek, uygulamanın ilk yılında Türkiye'de elde edilen sonuçlar, karşılaştırılabilmiş ve böylece değişen yönlerin görülmesi sağlanmıştır.

Denetçilerin yeni denetim standardı ile raporlara giren KDK'ları nasıl yorumladıklarını ve uyguladıklarını araştırdığı çalışmasında Doğan ve Arefaine (2017), denetçilerin öncelikli yükümlülüklerinden olan müşterinin sırlarının saklanması konusunun da dikkate alınması gerektiğini vurgulamışlardır. Araştırmacıların elde ettiği sonuçlardan biri de, standartla gelen ihtiyaca uygun KDK tespitlerini yaparken, şirketlerin mahremiyetlerinin de zarar görmemesinin sağlandığı şeklindedir.

Gökgöz (2018) ise Borsa İstanbul'da işlem gören 140 şirketin 2017 yılı denetçi raporlarında belirlenen KDK'ları incelediği çalışmasında 273 tane KDK belirlendiğini tespit etmiştir. 2017 yılının başlangıç olması nedeniyle çalışmasının sınırlı kaldığından söz ederek sonraki yıllarda yapılacak çalışmalarla, yeni uygulamanın beklenen faydayı sağlayıp sağlamadığının araştırılmasınının önemine dikkat çekmiştir.

Kilit denetim konularının ilk uygulamalarını ve sonuçlarını değerlendirmek için ilgili organizasyonlar ve öncelikle denetim şirketleri, bir yandan araştırmalarına ve bilgilendirme yayınlarına devam ederken, diğer yandan standart formatta, standart ifadelerle hazırlanan denetçi raporlarına eklenen şirketlere özel açıklamaların, değerlendirilmesi de sürecektir. 


\section{YÖNTEM}

Bu çalışmanın amacı, ülkemizde 2017 yılı itibariyle bağımsız denetçi raporlarında yer almaya başlayan "Kilit Denetim Konuları" nın içerik analizini yaparak, uygulamanın işleyişini 2017 ve 2018 yılı raporlarında karşılaştırmalı olarak incelemektir. Borsa İstanbulda işlem gören şirketlerden BIST30 endeksine kayıtlı şirketlerin, Kamuyu Aydınlatma Platformu (KAP) üzerinden bağımsız denetçi raporları analiz edilerek bulgular oluşturulmuştur. Çalışmada analiz sonuçları değerlendirilirken benzer veya aynı başlıktaki kilit denetim konularının denetçi raporunda tanımlanış şekillerine öncelik verilmiştir. BDS 701 kapsamında denetçi raporunda yer verilen kilit denetim konularının öncelikli amacının işletmeye özel duruma açıklık getirmesi ihtiyacı olduğundan, KDK olarak belirlenen konuların 2017 ve 2018 yılları raporlarından karşılaştırması yapılarak, gelişme ve farkların tespiti hedeflenmiştir.

\section{BULGULAR}

Çalışma sonuçları değerlendirilirken aynı faaliyet alanında bulunan şirketlerin denetçi raporlarında yer alan KDK'ları içerikleri, kendi içinde 2017 ile 2018 yılları raporlarında yer alan unsurlar açısından karşılaştırılmıştır.

\section{Tablo 1: Bankalar - KDK dağılımı}

\begin{tabular}{|lcc|}
\hline Kilit Denetim Konusu & $\mathbf{2 0 1 7}$ & $\mathbf{2 0 1 8}$ \\
\hline Krediler sınıflama- değer düşüklüğü & 6 & \\
TFRS 9 uygulamalarına geçiş - riskten korunma* & & 6 \\
Çalışanlar emeklilik planları & 6 & 6 \\
Bilgi teknolojileri denetimi & 1 & 1 \\
Türev finansal araçlar & 1 & 1 \\
$*$ TFRS 9 Finansal Araçlar Standardı 2018 yılı itibariyle uygulamaya başlanmıştır. \\
\hline
\end{tabular}

Tablo 1'de BIST 30'da yer alan 6 banka için seçilen KDK'larının iki ana konuda ağırlık kazandığı görülebiliyor. Özellikle TFRS 9 Finansal Araçlar standardının uygulamaya girişi ile ilgili süreç tüm bankaların finansal raporlarına etki edişi açısından belirleyici olmaktadır.

Tablo 2: Otomotive Sektörü - KDK Dağılımı

\begin{tabular}{|lcc|}
\hline Kilit Denetim Konusu & 2017 & 2018 \\
\hline Nakit akış riskinden korunma muhasebesi & 1 & 1 \\
Garanti gider karşıı̆ı & 2 & 2 \\
Aktifleştirilmiş geliştirme maliyetleri & 1 & 1 \\
Finans sektörü faaliyetlerinden alacaklar & 1 & 1 \\
Kıdem tazminatı karşılığı & 1 & \\
\hline
\end{tabular}

Otomotive sektöründeki 2 şirket için, şirketlerin satışlarıyla ilgili verilen parça garantileri karşılıkları ortak KDK olarak geçerken, diğerleri şirketlerin yönetim şekillerine bağlı olarak belirlenmişlerdir.

\section{Tablo:3 Havacılık Sektörü - KDK Dağılımı}

\begin{tabular}{|lcc|}
\hline Kilit Denetim Konusu & 2017 & 2018 \\
\hline Hasılatın muhasebeleştirilmesi & & 2 \\
Yolcu yükümlülüğü & 2 & 1 \\
Sık uçuş programının muhasebeleştirilmesi & 1 & 1 \\
Uçakların muhasebeleştirilmesi & 1 & 1 \\
Teslim bakım karşılıkları - kiralık uçaklar & 1 & 1 \\
Türev finansal araçlar - finansal riskten korunma muhasebesi & 1 & 1 \\
\hline
\end{tabular}

Havacılık sektöründen 2 şirket için hasılatın muhasebeleştirilmesi dışındaki tespitler, yönetim şekilleri ve işletmelerin temel işleyişlerindeki farkları da ortaya koymaktadır. 
Tablo 4: BIST 30'da yer alan iki haberleşme şirketi için KDK tespitleri

\begin{tabular}{|lcc|}
\hline Kilit Denetim Konusu & 2017 & 2018 \\
\hline & & \\
Karşılıklar ve koşullu borçlar & 1 & 1 \\
Hasılatın muhasebeleştirilmesi - TFRS 15 & 2 & 2 \\
Duran varlıklarda aktifleştirme & 1 & 1 \\
Bilgi teknolojilerinin genel kontrolleri & 1 & \\
Türev araçların ölçülmesi ve muhasebeleştirilmesi & 1 & 1 \\
TFRS 16 kiralamalar standardının ilk kez uygulanması & & 1 \\
Yurtdısıı yatırımları & 1 & 1 \\
Ihtilaflar, davalar ve koşullu borçlar & 1 & 1 \\
TFRS 9 uygulamalarına geçiş & & 1 \\
Ertelenmiş vergi varlığının değerlemesi & 1 & 1 \\
Şerefiye ve diğer duran varlıklarda değer düşüklüğü & 1 & 1 \\
\hline
\end{tabular}

Haberleşme sektöründen iki şirketin raporunda yer alan KDK seçimlerinde, hasılatın muhasebeleştirilmesi ortak başlıkta görülürken, ortak konu koşullu borçlar ayrı başlıklarda değerlendirilmiştir. Haberleşme sektörünün pazar dinamiklerine ve yasal düzenlemelere bağlı olarak, faaliyetlerin ve finansalların raporlanmasında özellik oluşturan konular da çeşitlidir.

\section{Tablo 5: Demir Çelik Şirketleri - KDK tespitleri}

\begin{tabular}{|lcc|}
\hline Kilit Denetim Konusu & 2017 & 2018 \\
\hline Hasılatın kaydedilmesi & 1 & 1 \\
Üretim miktarı yöntemi ile amortisman hesaplaması & 1 & 1 \\
Şerefiye değer düşüklüğü & 1 & \\
Stok değer düşüklüğü & 1 & 1 \\
Yatıım teşvikleri & 1 & \\
Yapılmakta olan yatırımların sınıflandırılması, yararlı ömürler & 1 & 1 \\
Maddi duran varlıkların yeniden değerlemesi & & 1 \\
Kredi sözleşmelerine göre finansal oranlara uyum & 1 & \\
\hline
\end{tabular}

Demir Çelik sektöründen 2 şirket için stok değer düşüklüğü, kredi sözleşmelerinden doğan yükümlülükler gibi seçilmiş KDK'lar, yönetim politikalarına dikkat çekmek açısından belirleyici olmaktadır.

\section{Tablo 6: Madencilik Şirketleri - KDK tespitleri}

\begin{tabular}{|lcc|}
\hline Kilit Denetim Konusu & 2017 & 2018 \\
\hline Hasılatın kaydedilmesi & 2 & \\
Stoklar & 2 & \\
Üretim miktarı yöntemi ile amortisman hesaplaması & 2 & 2 \\
Aktifleşen maden varlıkları & & 2 \\
Yasal riskler & & \\
\hline
\end{tabular}

Madencilik sektöründen iki şirket için 2018 yılında yasal risklere bağlı süreçler belirleyici olurken, 2017 yılında hasılatın kaydedilmesi ve stok hesapları sektöre özel konular olarak yer almıştır.

Tablolarda özetlenen BIST 30 şirketlerinin 2017-2018 yılları bağımsız denetçi raporlarında yer alan KDK'ların içerikleri, genel tanımlamalarla, aşağıdaki gibidir:

$\checkmark$ iş koluna ait özellik oluşturan konular,

$\checkmark \quad$ Yönetim politika ve düzenlemeleri,

$\checkmark \quad$ Mevzuata uyum ve değişen uygulamalara geçiş süreçleri,

$\checkmark$ Finansal risk yönetim süreçleri,

$\checkmark$ Yasal riskler.

Bu konularda bilgi kullanıcılarının dikkatini çekerek, denetçi raporundan sağlanan faydayı ve rapora duyulan güveni arttırma hedefi vurgulanmıştır. 


\section{SONUÇ VE ÖNERILER}

Olumlu denetçi görüşü veren raporlara rağmen ortaya çıkan şirket skandalları ve ekonomik stres koşullarında gözlemlenen beklenmedik finansal zayıflıklara, küreselleşen iş hayatında daha çok rastlanması, bilgi kullanıcıları açısından farklı ihtiyaçları ortaya çıkartmıştır. Denetçilerin belirli standartlara göre yaptıkları finansal tablo doğrulamalarına ilave olarak, ek bilgi ihtiyacı ortaya çıkmıştır. Denetçiler rapor kullanıcılarına yönelik olarak ihtiyaç duyulan finansal olmayan bilgiler için KDK'ları kullanmaya başlamışlardır. KDK'ların hedeflenen denetçi raporunun iletişim değerini arttırmadaki en önemli rolü denetlenen şirkete, şirketin faaliyetlerine özel olmasıdır. Örnekler üzerinden yapılan analizler ve bu konuda yapılan çalışmalar değerlendirildiğinde, ele alınan KDK'lar bilgi kullanıcılarına ek bilgi sağlamak açısından yararlı olsa da, mevcut uygulamaların henüz şirkete özel olma koşulunu karşılamadığı ileri sürülebilir.

Çalışmada ele alınan örnekler üzerinden değerlendirildiğinde, KDK ele alınış şekillerindeki genel ifadelerin nedeni, uzun yıllardır süre gelen standart rapor formatlarına dâhil olması beklenen ve sınırları çizilmemiş bilgilerin ifade edilmesindeki zorluk gibi görünmektedir. Standart denetçi raporlarındaki tanımlamalar gruplar halinde, belirli kalıplarda olduğundan, alışılagelmiş formatın dışına çıkılması nedeniyle uygulamada tereddütler olduğu varsayılabilir. Zaman içinde bilgi kullanıcılarının KDK'larından yararlanmak konusundaki pratiklerinin artması ve hatta bu konuda bilgi taleplerinin oluşması da, denetçi raporundaki finansal olmayan bilgilerin içerik olarak gelişmesine kaçınılmaz olarak katkı sağlayacaktır. Gerek bilgi kullanıcılarının doğrudan veya dolaylı ihtiyaçları, gerekse de şirketlerin kendi raporlarında yer alan bilgiler ile olan değerlendirmeleri, KDK'larının uygulamadaki durumunu geliştirecektir.

BDS 701 standardının henüz yeni bir uygulama olması nedeniyle, bu konuda yapılacak inceleme ve araştırmaların, hazırlanacak akademik çalışmaların da, şirketler, bilgi kullanıcıları ve bağımsız denetçiler için büyük katkı sağlayacağından söz etmek yanlış olmayacaktır.

\section{KAYNAKÇA}

Apollos, N.N., Onuoha, L., Aguguom, A.T., (2016), The New Auditors' Reporting Standarts And The Audit Expectation Gap, International Journal of Advanced Academic Research, Social \& Management Sciences, 2, (11) , 118-133

Ciğer, A., Çopur Vardar, G., Kınay, B. (2018), Borsa İstanbul'a Kayıtı Şirketlerin Kilit Denetim Konularının Incelenmesi Üzerine Bir Araştırma, ICAFR'18,

Doğan, A. (2018), Bağımsız Denetimde Yeni Bir Yaklaşım: Kilit Denetim Konuları, Muhasebe Bilim Dünyası Dergisi, Mart 2018, $20(1), 65-89$.

Doğan, B., Arefaine, B., (2017), The Implementation of ISA 701 - Key audit Matters: Empirical Evidence on Auditors' Adjustment in The New Audit report, Master tezi, UppsalaUniversity, Department of Business Studies.

Gökgöz, A. (2018), Kilit Denetim Konularının bağımsız Denetçi Raporunda Bildirilmesi ve Borsa İstanbul'da İşlem Gören İşletmeler Üzerine Bir Araştırma, Journal Of Accounting, Finance and Auditing Studies, Vol4, Iss2, 126-138

Kavut, L., Güngör, N. (2018), Bağımsız Denetimde Kilit denetim Konuları: BIST-100 Şirketlerinin 2017 Yılı Analizi, Muhasebe Enstitü Dergisi 16 (59), 59-70. Retrieved from http://dergipark.gov.tr/meder/issue/39328/463560i

Kavut, L., Taş, O., Şavlı,T. (2009). Uluslararası Denetim Standartları Kapsamında Bağımsız Denetim, iSMMMO Yayın No.130, İstanbul

Yanık, S., Karataş, M., (2017), Denetim Raporlarının Geleceği: Yeni Düzenlemeler ve Ülke Uygulamaları, Muhasebe ve Finansman Dergisi,

https://www.ifac.org/system/files/publications/files/Auditor-Reporting-Toolkit-KAM-Overview.pdf

http://www.kgk.gov.tr/Portalv2Uploads/files/Duyurular/v2/BDS/BDS\%20701.pdf

https://www.accaglobal.com/in/en/professional-insights/global-profession/key-audit-matters.html

http://www.dt-audit.com/dosyalar/Kutuphane/Ba\%C4\%9F\%C4\%B1ms\%C4\%B1z\%20Denetim\%20Standard\%C4\%B1\%20\%28BDS701\%29.pdf

https://www2.deloitte.com/content/dam/Deloitte/ch/Documents/audit/ch-en-audit-benchmarking-auditors-report.pdf

https://home.kpmg/kh/en/home/services/audit/auditmethodology.html 